\title{
Stochastic Model on Three-Similar Units Three- Phased Mission System with FCFS Repairs Pattern
}

\author{
Sudesh Kumari, Rajeev Kumar
}

\begin{abstract}
The paper allocates a stochastic model on threesimilar units three-phased mission system. The developed system consists of units working in parallel, series and parallel configurations respectively. Initially, the three similar units are operational. Each component has only three states: good, degraded and failed. In this case, the single repair facility that repairs the units in first come first serve (FCFS)pattern has been thought of. Using Semi-Markov Process and regenerative point techniques, various measures of the system performance at each phase are obtained. The system has been analyzed graphically taking a particular case. Various conclusions are made regarding the reliability and cost consideration of the system at each phase as well as for the whole system(as combined Phase I, Phase II, Phase III).
\end{abstract}

Keywords: Three Phased Mission System, Parallel Configuration, Series Configuration, Reliability, Profit.

\section{INTRODUCTION}

A phased mission system is a system that performs a sequence of various tasks in different time periods undergoing different environmental conditions and success criteria. Compared to a single phased system, it consists of multiple, consecutive and non-over lapping phases (time periods) of operations, during which the system's configuration, the phase duration, system performance, components' behavior, the parameters like failure rates, repair rates of the components may vary from one phase to alternative phase.If each phase completes successfully the task, then phased mission system obtains an overall mission success. By failing of any of these phases, the mission may fail. The phased mission system must be evaluated to obtain the reliability of each phase. As an application, an aircraft mission has many phases including taxing, take-off, cruising, descending and landing phases [6].

In the recent years, the modeling on phased mission systems that involves single or multi-phases with several components [1] has been widely investigated and many different approaches appear in the literature to evaluate the reliability of the phased mission system. Theresearchers [1][7]

Manuscript received on March 22, 2021.

Revised Manuscript received on March 30, 2021.

Manuscript published on April 30, 2021.

* Correspondence Author

Sudesh Kumari*, Research Scholar, Department of Mathematics, M.D. University, Rohtak-124001, Haryana, India

Rajeev Kumar, Professor \& Head, Department of Mathematics, M.D. University, Rohtak-124001, Haryana, India

(C) The Authors. Published by Blue Eyes Intelligence Engineering and Sciences Publication (BEIESP). This is an open access article under the CC BY-NC-ND license (http://creativecommons.org/licenses/by-nc-nd/4.0/) have focused on the problem of phase independence, mainly using Fault Tree Analysis, Boolean algebra and Petri Nets. But with the growing number of the system construction, it is more difficult to be applied to these systems. Keeping this view, thepaper allocates a stochastic model on a threesimilar units three-phased mission system with relation to its reliability and cost consideration.

\section{MODEL DESCRIPTION}

In this paper, a stochastic model is developed with three similar units working in parallel, series and parallel configurations respectively. The model is based on separate phased modeling. The duration of each phase is fixed and in all phases, units are initially considered to be operative. Each unit has only three states: good, degraded and failed. In this case, the single repair facility that repairs the units in first come first serve (FCFS) pattern has been thought of.If any one of unit fails, the system goes for repair to the repairman. The system slowly works and goes to degradation state. It is assumed that the failure rate and hence repair rate in successive phases varies, however within the phase the rates remain constant. If all the units fail, the system stopped and goes to completely failed state. As operating life of the system consists of a series of separate time intervals/phases, the reliability of whole phased mission is taken as combined reliabilities of these phases. The phase III is assumed as phase I but rates are taken different. Using Semi-Markov Process and regenerative point techniques, various measures of the system performance at each phase have been obtained. The system has been analyzed graphically taking a particular case using exponential distribution. Various conclusions have been made regarding reliability of the system at each phase as well as for the whole system.

Other essential assumptions made in formulation of model are:

1. The system is as good as new after each repair.

2. Time to failures of a unit is exponentially distributed whereas other time distributions are general.

3. The transition times between the consecutive phases are instantaneous.

4. Switching is perfect and instantaneous.

5. All random variables are mutually independent.

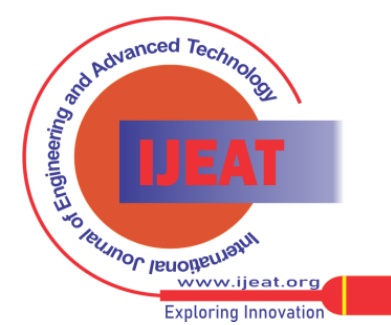




\section{Stochastic Model on Three-Similar Units Three-Phased Mission System with FCFS Repairs Pattern}

Table-1: Notations used in Description of the Model.

\begin{tabular}{|c|l|}
\hline Notation & \multicolumn{1}{c|}{ Description } \\
\hline $\mathrm{q}_{\mathrm{ij} \varphi \mathrm{j}}(\mathrm{t}) / \mathrm{Q}_{\mathrm{ij} \varphi \mathrm{j}}(\mathrm{t})$ & $\begin{array}{l}\text { Probability density function (P.d.f.)/Cumulative } \\
\text { distribution function (C.d.f.) of the first passage } \\
\text { time from a regenerative state } \mathrm{i} \text { to a regenerative } \\
\text { state } \mathrm{j} \text { or to a failed state } \mathrm{j} \text { without visiting to } \\
\text { any other regenerative state in }(0, \mathrm{t}] .\end{array}$ \\
\hline
\end{tabular}

\begin{tabular}{|c|c|}
\hline $\begin{array}{l}\mathrm{q}_{\mathrm{ij} \varphi \mathrm{j}}{ }^{(\mathrm{k})}(\mathrm{t}) / \mathrm{Q}_{\mathrm{ij} \varphi \mathrm{j}} \\
(\mathrm{k})(\mathrm{t})\end{array}$ & $\begin{array}{l}\text { P.d.f./ C.d.f. of the first passage time from a } \\
\text { regenerative state } \mathrm{i} \text { to a regenerative state } \mathrm{j} \text { or to } \\
\text { a failed state } \mathrm{j} \text { visiting state } \mathrm{k} \text { only once in }(0, \mathrm{t}] \text {. }\end{array}$ \\
\hline $\mathrm{p}_{\mathrm{ij} \varphi \mathrm{j}}(\mathrm{t}) / \mathrm{p}_{\mathrm{ij} \varphi \mathrm{j}}{ }^{(\mathrm{k})}(\mathrm{t})$ & $\begin{array}{c}\text { Transition probability from regenerative state i to } \\
\text { a regenerative state j without visiting any other } \\
\text { state/and that of visiting state k once in }(0, \mathrm{t}] \\
\text { respectively. }\end{array}$ \\
\hline$\mu_{\mathrm{i} \varphi \mathrm{j}}$ & $\begin{array}{l}\text { Mean sojourn time in regenerative state } \mathrm{i} \text { before } \\
\text { transiting to any other state. If } \mathrm{T}_{\mathrm{i}} \text { denote the } \\
\text { sojourn time in state } \mathrm{i} \text {, then mean sojourn time in } \\
\text { state } \mathrm{i} \text { is } \\
\mu_{\mathrm{i}}(\mathrm{t})=\int_{0}^{\infty} \mathrm{P}\left(\mathrm{T}_{\mathrm{i}}>\mathrm{t}\right) \mathrm{dt}\end{array}$ \\
\hline $\mathrm{m}_{\mathrm{ij} \varphi \mathrm{j} /} \mathrm{m}_{\mathrm{ij} \varphi \mathrm{j}}{ }^{(\mathrm{k})}$ & $\begin{array}{l}\text { Contribution to mean sojourn time in regenerative } \\
\text { state i before transiting to regenerative state j / } \\
\text { visiting state k only once. }\end{array}$ \\
\hline$\Phi_{\mathrm{i} \varphi \mathrm{j}}(\mathrm{t})$ & $\begin{array}{l}\text { C.d.f. of the first passage time from regenerative } \\
\text { state i to a failed state. }\end{array}$ \\
\hline $\mathrm{UT}_{\mathrm{i}}(\mathrm{t})$ & $\begin{array}{r}\text { Probability that the system is in up-state at instant } \\
\text { t given that the system } \\
\text { entered regenerative state i } \\
\text { at time } \mathrm{t}=0 .\end{array}$ \\
\hline $\mathrm{DT}_{\mathrm{i} \varphi \mathrm{j}}(\mathrm{t})$ & $\begin{array}{c}\text { Probability that the system is in degraded state at } \\
\text { instant t given that the } \\
\text { system entered regenerative } \\
\text { state i at time } \mathrm{t}=0 .\end{array}$ \\
\hline $\mathrm{BR}_{\mathrm{i \varphi j}}(\mathrm{t})$ & $\begin{array}{l}\text { Probability that a repairman is busy in repairing } \\
\text { the failed unit at instant t, given that the system } \\
\text { started from the regenerative state } \mathrm{i} \text { at } \mathrm{t}=0 \text {. }\end{array}$ \\
\hline $\mathrm{VR}_{\mathrm{i} \varphi \mathrm{j}}(\mathrm{t})$ & $\begin{array}{l}\text { Expected number of visits by the repairman at } \\
\text { instant } t \text {, given that the system started from the } \\
\text { regenerative state } i \text { at } t=0 \text {. }\end{array}$ \\
\hline $\mathrm{Mu}_{\mathrm{i \varphi j}}(\mathrm{t})$ & $\begin{array}{l}\text { Probability that the system is up initially in } \\
\text { regenerative state i without passing through any } \\
\text { regenerative state or returning to itself through one } \\
\text { or more non- regenerative states. }\end{array}$ \\
\hline $\operatorname{Md}_{\text {ipj }}(\mathrm{t})$ & $\begin{array}{l}\text { Probability that the system is down initially in } \\
\text { regenerative state i without passing through any } \\
\text { regenerative state or returning to itself through one } \\
\text { or more non- regenerative states. }\end{array}$ \\
\hline $\mathrm{W}_{\mathrm{i} \varphi \mathrm{j}}(\mathrm{t})$ & $\begin{array}{l}\text { Probability that the repairman is busy with the } \\
\text { system initially in regenerative state i at time t } \\
\text { without passing through any regenerative state or } \\
\text { returning to itself through one or more non- } \\
\text { regenerative states. }\end{array}$ \\
\hline$*$ & $\begin{array}{l}\text { Symbol for Laplace Transformation, e.g. } \\
\mathrm{f}^{*}(\mathrm{~s})=\int_{0}^{\infty} \mathrm{e}^{-\mathrm{st}} \mathrm{f}(\mathrm{t}) \mathrm{dt}=\int_{0}^{\infty} \mathrm{e}^{-\mathrm{st}} \mathrm{dF}(\mathrm{t})\end{array}$ \\
\hline ** & Symbol for Laplace-Stieltjes transformation, e.g. \\
\hline
\end{tabular}

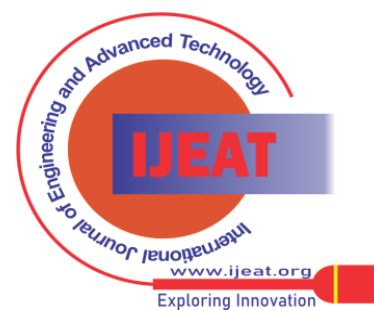

Fig.1.depicts several transitions states of the system. Initially the system is in working where all the phases are operative. The epochs of entry into the states 0,1 and 4 in phase I, states 5, 6 in phase II and states 7, 8, 11 in phase II are regenerative points and hence these are taken as degraded. State 3 in phase I, state 6 in phase II and state 10

Table-II: Notations used in Developed Model

\begin{tabular}{|l|l|}
\hline Notation & Description \\
\hline$\phi_{j}(t)$ & Time duration of $j^{\text {th }}$ phase $(j=1,2,3)$ \\
\hline$O$ & Operative Unit \\
\hline$F_{r}$ & $\begin{array}{l}\text { Unit is failed and is under repair }(i=1,2,3) \\
\text { resp. }\end{array}$ \\
\hline$F_{R}$ & $\begin{array}{l}\text { Failed unit is repair continuing from previous } \\
\text { state }\end{array}$ \\
\hline$F_{w}$ & Unit is failed and waiting for repair resp. \\
\hline$\lambda_{1} / \lambda_{2} / \lambda_{3}$ & $\begin{array}{l}\text { Failure rate of failed unit in } j^{\text {th }} \text { phase }(j=1,2, \\
\text { 3) resp. }\end{array}$ \\
\hline$\alpha_{1} / \alpha_{2} / \alpha_{3}$ & $\begin{array}{l}\text { Repair rate of repaired unit in } j^{\text {th }} \text { phase }(j=1, \\
2,3) \text { resp. }\end{array}$ \\
\hline$g_{1}(t) / g_{2}(t) / g_{3}(t)$ & $\begin{array}{l}\text { Pdf of time for repair of unit in } j^{\text {th }} \text { phase }(j=1, \\
2,3) \text { resp. }\end{array}$ \\
\hline$G_{1}(t) / G_{2}(t) / G_{3}(t)$ & $\begin{array}{l}\text { Cdf of time for repair of unit in } j^{\text {th }} \text { phase }(j=1, \\
2,3) \text { resp. }\end{array}$ \\
\hline
\end{tabular}




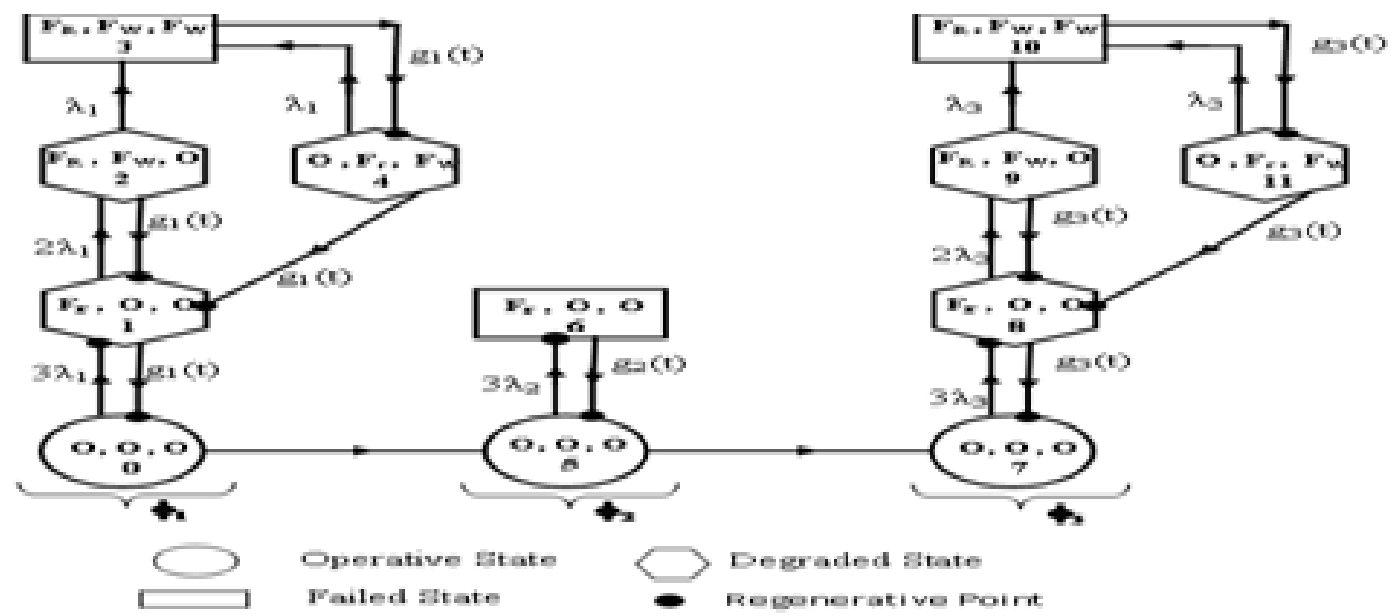

Fig.1. Three-Phased Mission System having Three-Similar Units with Parallel-Series-Parallel Configurations based on FCFS Repairs Pattern

\section{TRANSITION PROBABILITIES AND MEAN SOJOURN TIME}

\section{A. Transition Probabilities}

Various Transition Probabilities for each phase in steady state are obtained as:

$$
\mathrm{p}_{\mathrm{ij} \phi_{1}}=\lim _{\mathrm{s} \rightarrow 0} \mathrm{q}_{\mathrm{ij} \phi_{1}}^{*}(\mathrm{~s})=\lim _{\mathrm{s} \rightarrow 0} \mathrm{Q}_{\mathrm{ij} \phi_{1}}^{* *}(\mathrm{~s})
$$

Phase I

$$
\begin{aligned}
& \mathrm{p}_{01 \phi_{1}}=1 ; \\
& \mathrm{p}_{10 \phi_{1}}+\mathrm{p}_{11 \phi_{1}}^{(2)}+\mathrm{p}_{13 \phi_{1}}^{(2)}=1 ; \\
& \mathrm{p}_{10 \phi_{1}}+\mathrm{p}_{11 \phi_{1}}^{(2)}+\mathrm{p}_{14 \phi_{1}}^{(2,3)}=1 ; \\
& \mathrm{p}_{41 \phi_{1}}+\mathrm{p}_{43 \phi_{1}}=1 ; \\
& \mathrm{p}_{41 \phi_{1}}+\mathrm{p}_{44 \phi_{1}}^{(3)}=1
\end{aligned}
$$

Phase II

$$
\mathrm{p}_{56 \phi_{2}}=\mathrm{p}_{65 \phi_{2}}=1
$$

Phase III

$$
\begin{aligned}
& \mathrm{p}_{78 \phi_{3}}=1 ; \\
& \mathrm{p}_{87 \phi_{3}}+\mathrm{p}_{88 \phi_{3}}^{(9)}+\mathrm{p}_{8,10 \phi_{3}}^{(9)}=1 ; \\
& \mathrm{p}_{87 \phi_{3}}+\mathrm{p}_{88 \phi_{3}}^{(9)}+\mathrm{p}_{8,11 \phi_{3}}^{(9,10)}=1 ; \\
& \mathrm{p}_{11,8 \phi_{3}}+\mathrm{p}_{11,10 \phi_{3}}=1 ; \\
& \mathrm{p}_{11,8 \phi_{3}}+\mathrm{p}_{11,11 \phi_{3}}^{(10)}=1
\end{aligned}
$$

\section{B. Mean Sojourn Time}

Mean sojourn time and unconditional mean time for each phase are given by:

Phase I

$$
\begin{aligned}
& \mathrm{m}_{01 \phi_{1}}=\mu_{0 \phi_{1}} ; \\
& \mathrm{m}_{10 \phi_{1}}+\mathrm{m}_{11 \phi_{1}}^{(2)}+\mathrm{m}_{14 \phi_{1}}^{(2,3)}=\mathrm{m}_{41 \phi_{1}}+\mathrm{m}_{44 \phi_{1}}^{(3)}=\mu_{3 \phi_{1}} ; \\
& \mathrm{m}_{41 \phi_{1}}+\mathrm{m}_{43 \phi_{1}}=\mu_{4 \phi_{1}} ; \\
& \mathrm{m}_{10 \phi_{1}}+\mathrm{m}_{11 \phi_{1}}^{(2)}+\mathrm{m}_{13 \phi_{1}}^{(2)}=\mathrm{k}_{1}
\end{aligned}
$$

Phase II

$$
\begin{aligned}
& \mathrm{m}_{56 \phi_{2}}=\mu_{5 \phi_{2}} \quad ; \\
& \mathrm{m}_{65 \phi_{2}}=\mu_{6 \phi_{2}}
\end{aligned}
$$

Phase III

$$
\begin{aligned}
& \mathrm{m}_{78 \phi_{3}}=\mu_{7 \phi_{3}} ; \\
& \mathrm{m}_{87 \phi_{3}}+\mathrm{m}_{88 \phi_{3}}^{(9)}+\mathrm{m}_{8,11 \phi_{3}}^{(9,10)}=\mathrm{m}_{11,8 \phi_{3}}+\mathrm{m}_{11,11 \phi_{3}}^{(10)}=\mu_{10 \phi_{3}} ; \\
& \mathrm{m}_{11,8 \phi_{3}}+\mathrm{m}_{11,10 \phi_{3}}=\mu_{11 \phi_{3}} ; \\
& \mathrm{m}_{87 \phi_{3}}+\mathrm{m}_{88 \phi_{3}}^{(9)}+\mathrm{m}_{8,10 \phi_{3}}^{(9)}=\mathrm{k}_{2}
\end{aligned}
$$

\section{MEASURES OF SYSTEM PERFORMANCE}

Considering failed state as absorbing state, we obtain the recursive relation for mean time to system failure. Other measures of system performance as mean up time, mean degradation time, total fraction of time for which the repairman is busy, expected number of visits by the repairman are obtained. The steady state solutions for each phase and for the whole system are obtained as:

Phase I Mean Time to System Failure: $\quad \mathrm{T}_{0 \phi_{1}}=\frac{\mathrm{N}_{1 \phi_{1}}}{\mathrm{D}_{1 \phi_{1}}}$

$$
\text { Mean Up Time: } \quad \mathrm{UT}_{0 \phi_{1}}=\frac{\mathrm{N}_{2 \phi_{1}}}{\mathrm{D}_{2 \phi_{1}}}
$$$$
\text { Mean Degradation Time: } \mathrm{DT}_{0 \phi_{1}}=\frac{\mathrm{N}_{3 \phi_{1}}}{\mathrm{D}_{2 \phi_{1}}} \quad \text { Busy }
$$

Period of the Repairman: $\mathrm{BR}_{0 \phi_{1}}=\frac{\mathrm{N}_{4 \phi_{1}}}{\mathrm{D}_{2 \phi_{1}}}$

Expected Number of Visits by the Repairman: $\mathrm{VR}_{0 \phi_{1}}=\frac{\mathrm{N}_{5 \phi_{1}}}{\mathrm{D}_{2 \phi_{1}}}$

where

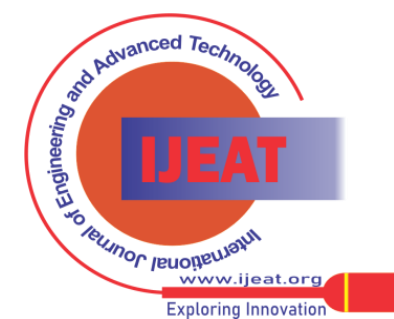




$$
\begin{aligned}
& \mathrm{N}_{1 \phi_{1}}=\mu_{0 \phi_{1}}\left(1-\mathrm{p}_{11 \phi_{1}}^{(2)}\right)+\mathrm{k}_{1} ; \\
& \mathrm{N}_{2 \phi_{1}}=\mu_{0 \phi_{1}} \mathrm{p}_{10 \phi_{1}} \mathrm{p}_{41 \phi_{1}} ; \\
& \mathrm{N}_{3 \phi_{1}}=\mu_{1 \phi_{1}} \mathrm{p}_{41 \phi_{1}}+\mu_{2 \phi_{1}} \mathrm{p}_{14 \phi_{1}}^{(2,3)} ; \\
& \mathrm{N}_{4 \phi_{1}}=\left(1+\mu_{1 \phi_{1}}\right) \mathrm{p}_{41 \phi_{1}}+\left(1+\mu_{4 \phi_{1}}\right) \mathrm{p}_{14 \phi_{1}}^{(2,3)} ; \\
& \mathrm{N}_{5 \phi_{1}}=\mathrm{p}_{10 \phi_{1}} \mathrm{p}_{41 \phi_{1}} ; \\
& \mathrm{D}_{1 \phi_{1}}=\mathrm{p}_{13 \phi_{1}}^{(2)} ; \\
& \mathrm{D}_{2 \phi_{1}}=\mu_{0 \phi_{1}} \mathrm{p}_{10 \phi_{1}} \mathrm{p}_{41 \phi_{1}}+\mu_{3 \phi_{1}}\left(\mathrm{p}_{41 \phi_{1}}+\mathrm{p}_{14 \phi_{1}}^{(2,3)}\right)(22-28)
\end{aligned}
$$

Phase IIMean Time to System Failure: $\mathrm{T}_{2 \phi_{2}}=\frac{\mathrm{N}_{1 \phi_{2}}}{\mathrm{D}_{1 \phi_{2}}}$

$$
\text { Mean Up Time: } \quad \mathrm{UT}_{2 \phi_{2}}=\frac{\mathrm{N}_{2 \phi_{2}}}{\mathrm{D}_{2 \phi_{2}}}
$$

Mean Degradation Time: $\mathrm{DT}_{2 \phi_{2}}=\frac{\mathrm{N}_{3 \phi_{2}}}{\mathrm{D}_{2 \phi_{2}}}$

Busy Period of the Repairman: $\quad \mathrm{BR}_{2 \phi_{2}}=\frac{\mathrm{N}_{4 \phi_{2}}}{\mathrm{D}_{2 \phi_{2}}}$

Expected Number of Visits by the Repairman:

$$
\mathrm{VR}_{0 \phi_{2}}=\frac{\mathrm{N}_{5 \phi_{2}}}{\mathrm{D}_{2 \phi_{2}}}
$$

where

$$
\begin{array}{ll}
\mathrm{N}_{1 \phi_{2}}=\mu_{5 \phi_{2}} ; & \mathrm{N}_{2 \phi_{2}}=\mu_{5 \phi_{2}} ; \\
\mathrm{N}_{3 \phi_{2}}=0 ; & \mathrm{N}_{4 \phi_{2}}=1+\mu_{6 \phi_{2}} ; \\
\mathrm{N}_{5 \phi_{2}}=1 \quad ; & \mathrm{D}_{1 \phi_{2}}=1 \\
\mathrm{D}_{2 \phi_{2}}=\mu_{5 \phi_{2}}+\mu_{6 \phi_{2}} &
\end{array}
$$

Phase IIIMean Time to System Failure: $T_{7 \phi_{3}}=\frac{N_{1 \phi_{3}}}{D_{1 \phi_{3}}}$

Mean Up Time:

$$
\mathrm{UT}_{7 \phi_{3}}=\frac{\mathrm{N}_{2 \phi_{3}}}{\mathrm{D}_{2 \phi_{3}}}
$$

Mean Degradation Time: $\mathrm{DT}_{7 \phi_{3}}=\frac{\mathrm{N}_{3 \phi_{3}}}{\mathrm{D}_{2 \phi_{3}}}$

Busy Period of the Repairman: $\quad \mathrm{BR}_{7 \phi_{3}}=\frac{\mathrm{N}_{4 \phi_{3}}}{\mathrm{D}_{2 \phi_{3}}}$

Expected Number of Visits by the Repairman:

$$
\mathrm{VR}_{7 \phi_{3}}=\frac{\mathrm{N}_{5 \phi_{3}}}{\mathrm{D}_{2 \phi_{3}}}
$$

where
Using the results of above three phases, combined result of the whole system is:

\section{Combined Phase Result}

Mean Time to System Failure: $T_{0}=\frac{N_{1}}{D_{1}}$

Mean Up Time:

$$
\begin{aligned}
& \mathrm{UT}_{0}=\frac{\mathrm{N}_{2}}{\mathrm{D}_{2}} \\
& \mathrm{DT}_{0}=\frac{\mathrm{N}_{3}}{\mathrm{D}_{2}}
\end{aligned}
$$

Busy Period of the Repairman: $\mathrm{BR}_{0}=\frac{\mathrm{N}_{4}}{\mathrm{D}_{2}}$

Expected Number of Visits by the Repairman:

where

$$
\begin{aligned}
\mathrm{N}_{1}= & \mu_{5 \phi_{2}}\left[\mu_{0 \phi_{1}}\left(1-\mathrm{p}_{11 \phi_{1}}^{(2)}\right)+\mathrm{k}_{1}\right]\left[\mu_{7 \phi_{3}}\left(1-\mathrm{p}_{88 \phi_{3}}^{(9)}\right)+\mathrm{k}_{2}\right] \\
\mathrm{N}_{2}= & \mu_{0 \phi_{1}} \mu_{5 \phi_{2}} \mu_{7 \phi_{3}} \mathrm{p}_{10 \phi_{1}} \mathrm{p}_{41 \phi_{1}} \mathrm{p}_{87 \phi_{3}} \mathrm{p}_{11,8 \phi_{3}} ; \\
\mathrm{N}_{3}= & 0 \\
\mathrm{~N}_{4}= & \left(1+\mu_{6 \phi_{2}}\right)\left[\left(1+\mu_{1 \phi_{1}}\right) \mathrm{p}_{41 \phi_{1}}+\left(1+\mu_{4 \phi_{1}}\right) \mathrm{p}_{14 \phi_{1}}^{(2,3)}\right] \\
& {\left[\left(1+\mu_{1 \phi_{3}}\right) \mathrm{p}_{41 \phi_{3}}+\left(1+\mu_{4 \phi_{3}}\right) \mathrm{p}_{14 \phi_{3}}^{(2,3)}\right] } \\
\mathrm{N}_{5}= & \mathrm{p}_{10 \phi_{1}} \mathrm{p}_{41 \phi_{1}} \mathrm{p}_{87 \phi_{3}} \mathrm{p}_{11,8 \phi_{3}} \\
\mathrm{D}_{1}= & \mathrm{p}_{13 \phi_{1}}^{(2)} \mu_{5 \phi_{2}}\left[\mu_{7 \phi_{3}}\left(1-\mathrm{p}_{88 \phi_{3}}^{(9)}\right)+\mathrm{k}_{2}\right]+\left[\mu_{0 \phi_{1}}\left(1-\mathrm{p}_{11 \phi_{1}}^{(2)}\right)+\mathrm{k}_{1}\right] \\
& {\left[\mu_{7 \phi_{3}}\left(1-\mathrm{p}_{88 \phi_{3}}\right)+\mathrm{k}_{2}\right]+\mathrm{p}_{8,10 \phi_{3}}^{(9)} \mu_{5 \phi_{2}}\left[\mu_{0 \phi_{1}}\left(1-\mathrm{p}_{11 \phi_{1}}^{(2)}\right)+\mathrm{k}_{1}\right] } \\
\mathrm{D}_{2}= & {\left[\mu_{0 \phi_{1}} \mathrm{p}_{10 \phi_{1}} \mathrm{p}_{41 \phi_{1}}+\mu_{3 \phi_{1}}\left(\mathrm{p}_{41 \phi_{1}}+\mathrm{p}_{14 \phi_{1}}^{(2,3)}\right)\right]\left[\mu_{5 \phi_{2}}+\mu_{6 \phi_{2}}\right] } \\
& {\left[\mu_{7 \phi_{3}} \mathrm{p}_{8 \phi_{3}} \mathrm{p}_{11,8 \phi_{3}}+\mu_{10 \phi_{3}}\left(\mathrm{p}_{11,8 \phi_{3}}+\mathrm{p}_{8,11 \phi_{3}}^{(9,1)}\right)\right] }
\end{aligned}
$$

The expected total profit $\left(\mathrm{P}_{0}\right)$ incurred to the system in steady state is given by

$$
\mathrm{P}_{0}=\mathrm{C}_{0} \mathrm{UT}_{0}+\mathrm{C}_{1} \mathrm{DT}_{0}-\mathrm{C}_{2} \mathrm{BR}_{0}-\mathrm{C}_{3} \mathrm{VR}_{0}-\mathrm{C}_{4} \text {, }
$$

where

$\mathrm{C}_{0}=$ revenue per unit up time of the system.

$\mathrm{C}_{1}=$ revenue per unit degradation time of the system.

$\mathrm{C}_{2}=$ cost per unit of busy period of the repairman. 
$\mathrm{C}_{3}=$ cost per visit of the repairman.

$\mathrm{C}_{4}=$ installation cost

\section{NUMERICAL COMPUTATION AND GRAPHICAL ANALYSIS}

The following particular case and values of parameters are considered for graphical purpose: $g_{i}(t)=\alpha_{i} e^{-\alpha_{i} t} \quad$ where $\mathrm{i}=1,2,3$

For the analysis purpose, various graphs have been plotted for mean time to system failure $\left(\mathrm{T}_{0}\right)$, mean up time $\left(\mathrm{UT}_{0}\right)$ and profit $\left(\mathrm{P}_{0}\right)$ of the system with respect to various estimated and assumed values of the failure $\operatorname{rates}\left(\lambda_{1}, \lambda_{2}, \lambda_{3}\right)$ and repair rates $\left(\alpha_{1}, \alpha_{2}, \alpha_{3}\right)$ and various costs is studied by plotting various graphs. The following interpretations and conclusions have been drawn from the graphs:

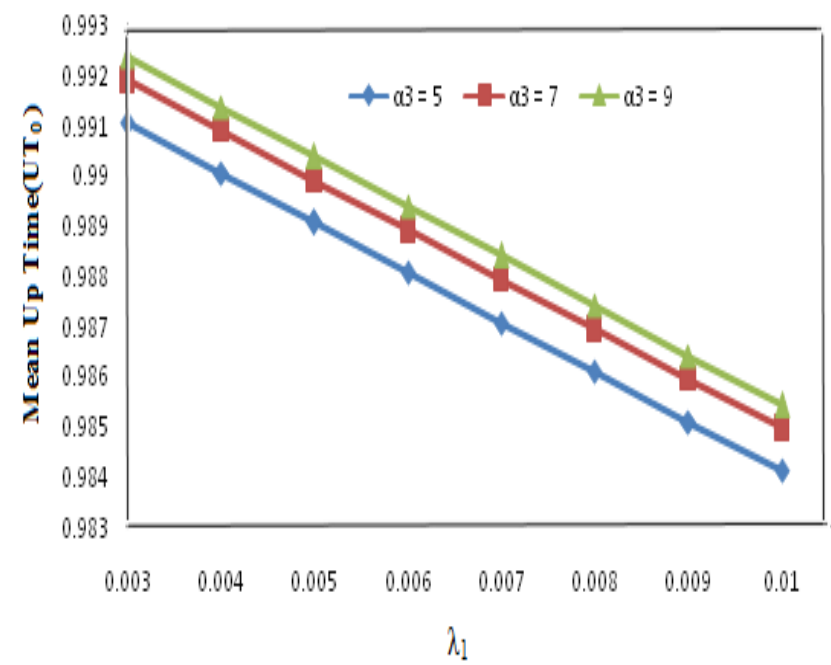

Fig.2. Mean up time of the system versus failure rate for phase $I\left(\lambda_{1}\right)$ for different values of repair rate for phase III $\left(\alpha_{3}\right)$.

Assumed values of other parameters: failure rate for phase II $\left(\lambda_{2}\right)=0.004$, failure rate for phase III $\left(\lambda_{3}\right)=0.005$, repair rate for phase I $\left(\alpha_{1}\right)=3$, repair rate for phase II $\left(\alpha_{2}\right)=4$.

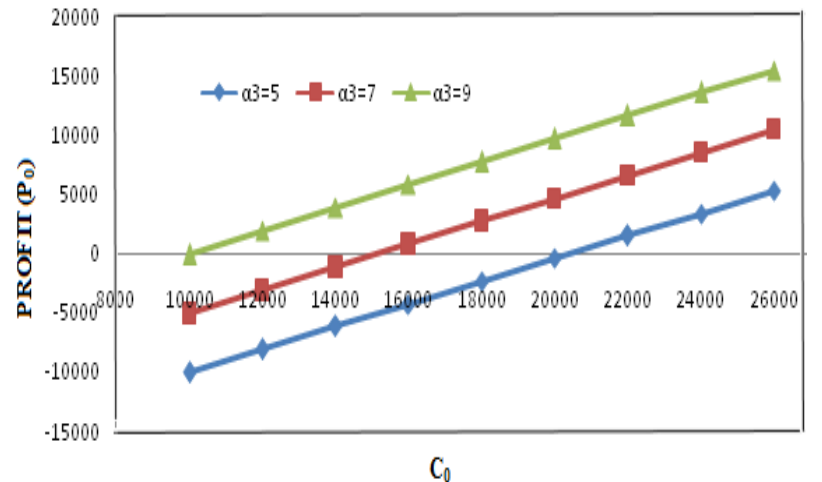

Fig.3. Profit incurred to the system versus revenue per unit uptime $\left(C_{0}\right)$ of the system for different values of repair rate for phase III $\left(\alpha_{3}\right)$

Assumed values of other parameters: failure rate for phase I $\left(\lambda_{1}\right)=0.003$, failure rate for phase II $\left(\lambda_{2}\right)=0.004$, failure rate for phase III $\left(\lambda_{3}\right)=0.005$, repair rate for phase I $\left(\alpha_{1}\right)=$ 3 , repair rate for phase II $\left(\alpha_{2}\right)=4, \mathrm{C}_{1}=30,000, \mathrm{C}_{2}=1000$, $\mathrm{C}_{3}=800, \mathrm{C}_{4}=20000$

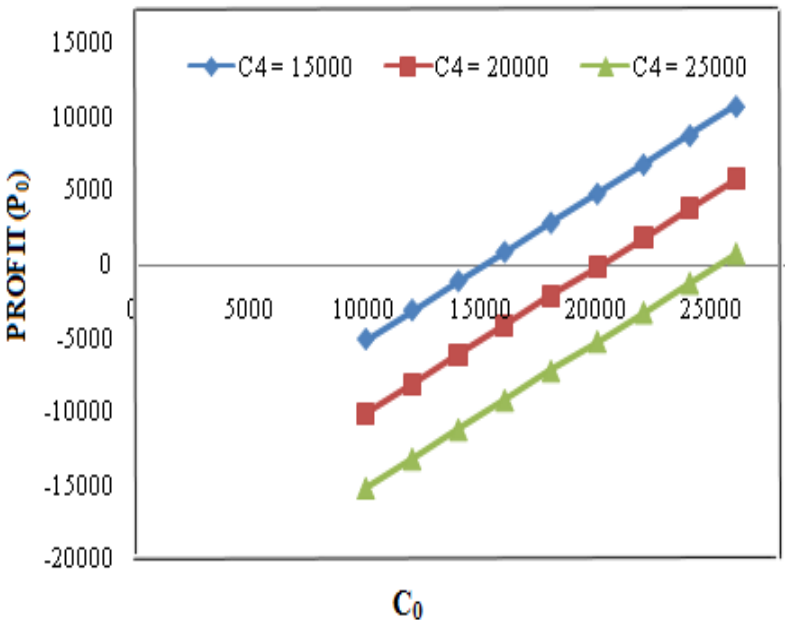

Fig.4. Profit incurred to the system versus revenue per unit uptime $\left(C_{0}\right)$ of the system for different values of installation cost $\left(\mathrm{C}_{4}\right)$.

The assumed values of other parameters: failure rate for phase I $\left(\lambda_{1}\right)=0.003$, failure rate for phase $\operatorname{II}\left(\lambda_{2}\right)=0.004$, failure rate for phase III $\left(\lambda_{3}\right)=0.005$, repair rate for phase I $\left(\alpha_{1}\right)=3$, repair rate for phase II $\left(\alpha_{2}\right)=4$, repair rate for phase III $\left(\alpha_{3}\right)=5, C_{1}=$ Rs.30,000, $C_{2}=$ Rs.1000, $\quad C_{3}=$ Rs.800.

\section{CONCLUSION}

We have explained three phases separately and have drawn some graphs related to mean up time and profit of the entire system w.r.t. failure rates for increasing values of repair rates. From the graphs, it can be interpreted as:

From fig. 2., it is clear that Mean up time $\left(\mathrm{UT}_{0}\right)$ of the system declines with increment in values of the failure rate for phase I $\left(\lambda_{1}\right)$ and inclines with higher values of repair rate for phase III $\left(\alpha_{3}\right)$.

Fig.3 declares that Profit incurred to the system inclines with increment in the values of revenue per unit uptime $\left(\mathrm{C}_{0}\right)$ of the system and also inclines with incrementsin values of repair rate $\left(\alpha_{3}\right)$. Also

(i) when $\alpha_{3}=5$, Profit incurred to the system inclines for $\mathrm{C}_{0}>$ Rs. 20430.3163, declines for $\mathrm{C}_{0}<$ Rs.20430.3163, remains unchanged for $\mathrm{C}_{0}=$ Rs. 20430.3163 and hence to attain Profit, revenue per unit uptime $\left(\mathrm{C}_{0}\right)$ of the system should be greater than Rs. 20430.3163.

(ii) when $\alpha_{3}=7$, Profit incurred to the system inclines for $\mathrm{C}_{0}>$ Rs. 15200.0196, declines for $\mathrm{C}_{0}<$ Rs. 15200.0196, remains unchanged for $\mathrm{C}_{0}=$ Rs. 15200.0196 and hence to attain Profit, revenue per unit uptime $\left(\mathrm{C}_{0}\right)$ of the system should be greater than Rs. 15200.0196.

(iii) when $\alpha_{3}=9$, Profit incurred to the system inclines for $\mathrm{C}_{0}>$ Rs. 10090.3677,declines for $\mathrm{C}_{0}<$ Rs. 10090.3677, remains unchanged for $\mathrm{C}_{0}=$ Rs. 10090.3677 and hence to attain Profit, revenue per unit uptime $\left(\mathrm{C}_{0}\right)$ of the system should be greater than Rs. 10090.3677.

Fig.4 shows that Profit incurred to the system inclines with increment in the values of revenue per unit uptime $\left(\mathrm{C}_{0}\right)$ of the system and declines with higher values of installation cost $\left(\mathrm{C}_{4}\right)$. Also

Published By:

Blue Eyes Intelligence Engineering

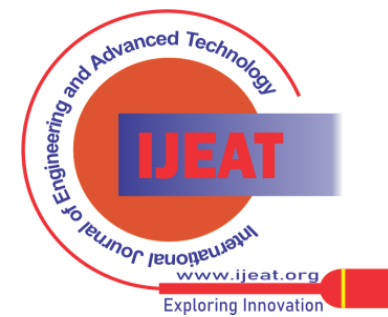




\section{Stochastic Model on Three-Similar Units Three-Phased Mission System with FCFS Repairs Pattern}

(i) when $\mathrm{C}_{4}=15,000$. Profit incurred to the system inclines for $\mathrm{C}_{0}>$ Rs.15135.5850,declines for $\mathrm{C}_{0}<$ Rs.15135.5850, remains unchanged for $\mathrm{C}_{0}=$ Rs.15135.5850 and hence to attain Profit, revenue per unit uptime $\left(\mathrm{C}_{0}\right)$ of the system should be greater than Rs.15135.5850.

(ii) when $\mathrm{C}_{4}=20,000$. Profit incurred to the system inclines for $\mathrm{C}_{0}>$ Rs. 20180.7824,declines for $\mathrm{C}_{0}<$ Rs. 20180.7824, remains unchanged for $\mathrm{C}_{0}=$ Rs. 20180.7824 and hence to attain Profit, revenue per unit uptime $\left(\mathrm{C}_{0}\right)$ of the system should be greater than Rs. 20180.7824.

(iii) when $\mathrm{C}_{4}=25,000$. Profit incurred to the system inclines for $\mathrm{C}_{0}>$ Rs. 25225.9796, declines for $\mathrm{C}_{0}<$ Rs. 25225.9796, remains unchanged for $\mathrm{C}_{0}=$ Rs. 25225.9796 and hence to attain Profit, revenue per unit uptime $\left(\mathrm{C}_{0}\right)$ of the system should be greater than Rs. 25225.9796.

Further, the model discussed can be fitted by the designers/users to the real situations. While fitting this model, one can take estimated values of the parameters so that one can improve the reliability of the system. The limits of failure/repair rates are/can be obtained for the system to give higher reliability, mean up time and profit that is quite useful for both the system designer and the system user.

\section{REFERENCES}

1. Dugan, J. B.,"Automated Analysis of Phased-Mission Reliability,”IEEE Trans. on Reliability,Vol.40(1), 1991,pp. 45-52.

2. Esary, J.D. and Ziehms, H.,"Reliability Analysis of Phased Missions, Reliability and Fault Tree Analysis," Proceeding of the Conference: Society for Industrial Applied Mathematics, Philadelphia, Pennsylvania, 1975, pp.213-236.

3. Huang, X., Coolen, Frank P.A., Coolen-Maturi, T., Zhang,Y.,“'A New Study on Reliability Importance Analysis of Phased Mission Systems," IEEE Transactions on Reliability,Vol. 69(2), 2019, pp. 522-532

4. Liu, C., Zhou, J. and Wang, H., "Reliability Analysis of Nonrepairable Phased-mission System by Proposed Sequence-enforcing Fault Tree Combined with Monte Carlo Simulation,” Proceedings of the $20204^{\text {th }}$ International Conference on Management Engineering, Software Engineering and Service Sciences, 2020, pp. 265-270.

5. Nowakowski, T., "Problems of Reliability Modelling of MultiplePhased Systems," Wroclaw University of Technology Publishing House, 2011, pp. 79-84

6. Tang,Z. and Dugan,J.B., "BDD-Based Reliability Analysis of PhasedMission Systems with Multimode Failures," IEEE Transactions on Reliability,Vol. 55(2), 2006, pp. 350-360.

7. Yan Hua, Gao Li, Qi Lei, Wan Ping., "Simplified Markov Model for Reliability Analysis of Phased-Mission System Using States Merging Method,"Journal of Shanghai Jiaotong University (Science)Vol. 23(3), 2018, pp.418-422.

\section{AUTHORS PROFILE}

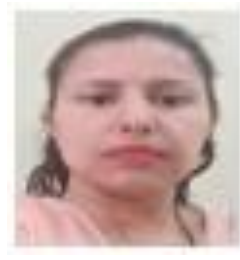

Sudesh Kumari, has completed her Master of Science (M.Sc.) in the year of 2010 and Master of Philosophy (M.Phil.) degree in subject of Mathematics in the year of 2012 from Department of Mathematics, Maharshi Dayanand University, Rohtak. She is gold medalist. She is pursuing her Ph.D. degree under the supervision of Prof. Rajeev Kumar, Head, Department of Mathematics, Maharshi Dayanand University, Rohtak. Now she is working also as an Assistant Professor in Govt. College Meham, Maharshi Dayanand University, Rohtak, Haryana India. She has published 6 research papers in various international journals and presented 15 research papers in different conferences/seminars. Her areas of interest are statistics and reliability modeling.

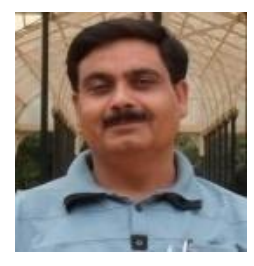

Dr. Rajeev Kumar, is presently working as Professor and Head, Department of Mathematics, Maharshi Dayanand University Rohtak. He is/ has been Chairman/ members of various academic/ research bodies. He has served as a Director, Department of Alumni Relations and Directorat Maharshi Dayanand University Rohtak from 2016 to 2020. He has completed his Ph.D. from Maharshi Dayanand University Rohtak in 1995. He has about 70 research publications in various National/ International journals of repute to his credit. His areas of interest are reliability modeling, information theory, operations research, bio-mathematics and statistical estimation. He has guided about 20 Ph.D./ M.Phil. Students for their theses/ dissertations work.

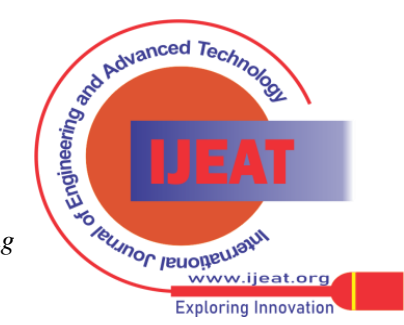

